\title{
Assessment of the strategies for reducing volatile organic compound emissions in the automotive industry in Taiwan
}

\author{
Chang-Tang Chang a,b,c,d,*, Ching-Hwa Lee ${ }^{\mathrm{a}, \mathrm{b}, \mathrm{c}, \mathrm{d}}$, \\ Yo-Ping $\mathrm{Wu}^{\text {a,b,c,d }}$, Fu-Tien Jeng a,b,c,d \\ a Department of Environmental Engineering, National I-Lan Institute of Technology, No. 1, \\ Sheen-Long Road, I-Lan City, Taiwan, ROC \\ ${ }^{\mathrm{b}}$ Department of Environmental Engineering, Da-Yeh University, Chung-Hwa City, Taiwan, ROC \\ ${ }^{c}$ Department of Chemical Engineering, National I-Lan Institute of Technology, I-Lan City, Taiwan, \\ $R O C$ \\ ${ }^{\mathrm{d}}$ Graduate Institute of Environmental Engineering, National Taiwan University, Taipei City, Taiwan,
} $R O C$

Received 28 September 1999; received in revised form 9 June 2001; accepted 20 July 2001

\begin{abstract}
Automotive coating processes must adhere to consumer preferences, such as anti-rust, weatherproof and overall appearance of coatings. Some solvents are added as thinners and additives to avoid excessive viscosity of the coating materials and to increase facility in painting. In addition, solvents use in the automotive industry in Taiwan is estimated at 7200 ton/year in major coating processes, including electrodeposition coating, primer coating, top coating, and bar coating. Volatile organic compounds (VOCs) are not easily controlled. It is important to know the VOC-pollution sources and emission characteristics before treating the VOCs in automobile industry. In this study, 80 stacks in five factories were tested to evaluate emission characteristics in each VOC-source. After examining the flue gases, the amount of solvents used for washing spray gun and base coating are estimated at 3350 ton/year, and about 1700 ton/year for primer coat and clear coat. The organic solvents include toluene, xylene, ethyl acetate, $n$-butyl acetate, and ketone. VOC emission factors from each plant ranges between 500 and $650 \mathrm{~g}-\mathrm{VOC} / 1$ coating. To reduce the amount of coating and waste liquor, recommended methods include increasing gun spray efficiency, lengthening the same color-painting period, reducing the solvent content in painting and
\end{abstract}

\footnotetext{
* Corresponding author. Tel.: + 886-39-357400-741; fax: + 886-39-359674.
}

E-mail address: ctchang@mail.ilantech.edu.tw (C.-T. Chang).

0921-3449/02/\$ - see front matter (C) 2002 Elsevier Science B.V. All rights reserved.

PII: S0921-3449(01)00088-X 
adding treatment equipment. The high-solid content painting, waterborne coat, and powder coat should be used for traditional painting. Moreover, carbon adsorption bed and zeolite rotator recovery system can replace scrubbers, since they can be used as solvent recovery equipment. (C) 2002 Elsevier Science B.V. All rights reserved.

Keywords: Solvent recovery; Painting processes; Automobile production; Volatile organic compounds

\section{Introduction}

Emissions of these volatile organic compounds (VOCs) cause serious odor problems. The odor problems lead to disputes between the factories and residents near the plants. Furthermore, emissions of these VOCs may cause the adverse health effects. The vapors are absorbed rapidly from the lungs and taken up readily from the gastrointestinal tract, but poorly through the skin. They are deposited in adipose tissue and in the central nerve system (Air Resources Board, 1978). The effects of VOCs on the central nerve system are related to dizziness, weakness, confusion, and co-ordination (National Archives and Records Administration, 1998; US EPA, 1977). Sniffing of VOCs has also resulted in some cases in life threatening metabolic acidosis characterized by a high anion gap or by hyperchloremia and other findings consistent with renal tubular acidosis (Wadden et al., 1995; Smith and Brown, 1993).

The VOCs are not easy controlled, since the flow rate of flue gas is large and the composition of VOCs is very complicated (Fu et al., 2001; Japanese EPA, 1999). Generally, the VOCs are treated according to the pollution control systems in the car production plants. The catalytic incinerator and combustion chamber, especially regenerative thermal oven, are used to control the VOCs from the oven (Wolkoff et al., 1999; Tichenor and Palazzolo, 1997), while the use of an absorber and zeolite rotator can also be used to manage the flue gas from the paint booth (Ergas, 1993; Findlay and Nirmalakhandan, 1996). It is important to know the VOC-pollution sources and emission characteristics before treating the VOC emissions in automobile industry. In this paper, we study the VOC emissions and propose emission reduction measures for the automotive coating process.

\subsection{Solvent consumption of the automotive industry}

Accelerated economic development and increased living standards in Taiwan have made automobiles the conventional means of transportation. In light of increased personal income levels and fierce market competitiveness, consumers highly prioritize appearance and model, when selecting vehicles. To satisfy consumers' preferences, except for fitting basic functions of anti-rust and weatherproof, automobile coating process must undergo innovative advances with respect to the color effect to gain a competitive advantage in the car market. Although increasing the consumers' range of selection, a wide variation of colors has created pollution side effects in the automobile coating process. 
The automobile coating process involves adding some solvents as thinners and additives to avoid excessive viscosity of the coating materials and to increase facility in working. Conventionally used thinners contain VOCs, such as toluene, xylene, ethyl acetate, and $n$-butyl acetate (Chang and Jeng, 1998). Owing to their low boiling point and high volatility, these thinners can easily seep out of the coating materials during the coating or drying processes, subsequently causing pollution. The impacts of VOCs are largely found in photochemical reaction (smog forming), plant devastation, and pulmonary disorders. Moreover, a high concentration of VOCs causes acute poisoning in humans and even leads to fatal accidents.

Six automotive manufacturers in Taiwan produce passenger cars, sedans, station wagons, vans, and trucks. The annual revenue generated by automotive manufacturers ranges from US 40 to 400 million dollars. Total consumption of volatile organic solvents is about 407000 ton/year of which $\approx 100700$ ton/year is used in surface coating. The solvents used in the automotive industry, account for 6900 ton/year (Industrial Pollution Control Center, 2000). In general, recovering VOCs with wet scrubbers is rather difficult, since the liquor contains several solvents. Therefore, in this study, we assess available solvent recovery strategies to understand their efficiency.

\subsection{Manufacturing processes}

To satisfy the customer's requirement and prolong the automobile's life, the car body must undergo a series of complex coating procedures to ensure the desired features, such as weatherproofing, corrosion-resistance, and luster and attractive appearance. Typical coating processes include pre-treatment, electrodeposition coating, electrodeposition coating drying, sealant, PVC sound-proof painting and stone-proof painting, primer coating/guide coating, primer coat drying, primer coat grinding, top coating, top coat drying, patching, checking and waxing (Fig. 1). In general, several layers of coating are necessary in car painting processes. The stainless steel car bodies are initially pre-treated with a cleanup agent, hot bath drying, degreasing, and surface adjustment. The car bodies are then hung by a cable inside electrodeposition chambers. The electrodeposition processes include coating, settling, and drying. The VOCs emission rate (ER) is relatively small in above processes, since the electrodeposition solvents are waterborne. The third step is makeup with sealant, PVC soundproof painting and stone-proof painting. The VOC ER can also be neglected, since the amount of solvent used is only slight.

As an important part of the painting process in vehicle production, primer coating is used to ensure anti-rust features of a car. The drying processes are performed after coating, producing a large amount of VOC emissions. Another important process is top coating, which is proceeded with solid coating or metallic coating to ensure an overall good appearance. The remaining processes are patching, checking and waxing to ensure a good external appearance. From the perspective of emission characteristics and manufacturing processes, recovery in the primer and top coating can be achieved. Therefore, we investigate the VOC emission characteristics according to different processes and assess the control strategies as well. 


\subsection{The strategies for reducing the emission of VOCs}

To reduce the amount of coating and waste liquor, recommended methods are increasing gun spray efficiency, increasing the same colors painting period, reducing the solvent content in painting and adding treatment equipment. The high-solid content painting, waterborne coat, and powder coat should be used for traditional painting. Moreover, carbon adsorption bed and zeolite rotator recovery system can replace scrubber, since they can be used as solvent recovery equipment.

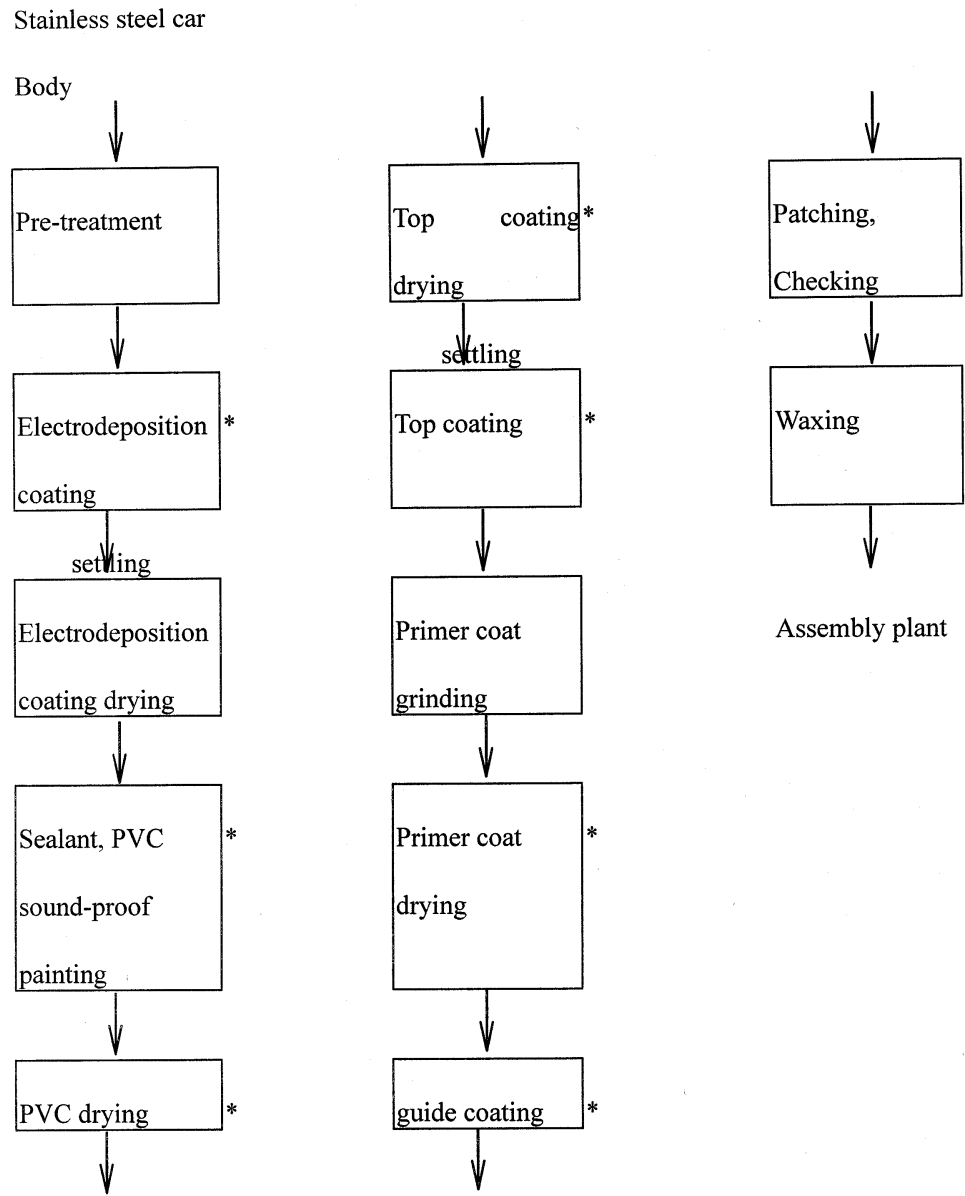

Note: the asterik' ${ }^{\prime}$ ' denotes the pollution sources

Fig. 1. Painting processes of an automobile. 


\section{Materials and methods}

\subsection{Classification of pollution sources}

Major pollution sources during coating processes must be identified. The volume and composition of the flue gases in 80 stacks are measured. The pollution sources include electrodeposition coating, sealant, PVC soundproof painting, stone-proof painting, primer coating, top coating, primer coat, topcoat drying, patching, waxing, anti-rust waxing, and coating equipment-cleaning processes. In this study, we analyze the solvent used in each process and VOC emission characteristic to identify the most important sources.

\subsection{Identification of emission characteristics}

To understand the emission characteristics, this study performs site testing of VOCs emission. The testing method is based on testing method B according to the US Federal Government's regulations of VOCs testing method (National Archives and Records Administration, 1998). The method uses gas chromatography (GC) to analyze concentration of compounds in the flue gases. The HNU portable GC, model-311, with GC column SP-1200, $1.75 \%$ Bentonite $34,6^{\prime} \times 1 / 8^{\prime \prime}$ was used to analyze the VOC composition. There are six major automobile factories in Taiwan. These plants possess about 110 stacks that release VOCs. Of the six automobile plants, 80 stacks in five factories were tested to evaluate emission characteristics of each VOC-source. The measurements are also executed in different painting processes, such as high-solid content painting waterborne coat, and powder coat, to assess the VOCs ER. Test items included temperature, flow velocity, VOC composition and concentration before and after treatment equipment.

The sampling procedures compose of preparing and preheating the sampling system, connecting the auto-analysis system, and combining with the datalog system. The sampling volume is about 11 for each run. However, the flue gas injected to $\mathrm{GC}$ is only $300 \mathrm{~cm}^{3}$. Four samples were examined for each stack.

\subsection{Estimation of VOCs ER}

Organic solvents used in automotive surface coating include coating and thinner. Owing to its low boiling point and strong volatile, solvents are liable to escape from coating materials during the coating process, resulting in VOC emission. VOC ERs (theoretical ER) can be estimated from the consumption of ingredient, thinner, and the ones used for washing spray gun in each process. Moreover, the VOC ER can be calculated with the flow rate and VOC concentration in different emission sources.

The overall ER, of each pollution source was illustrated as Eq. (1). Generally, the operating time is $8 \mathrm{~h}$ in 1 day and 11 months in 1 year.

$$
\mathrm{ER}=V \times \mathrm{As} \times \mathrm{Ci}
$$


where $V$ is the wind velocity $(\mathrm{m} / \mathrm{s})$; As, section area of stack $\left(\mathrm{m}^{2}\right)$ and $\mathrm{Ci}$, average concentration of each component $\left(\mathrm{mg} / \mathrm{m}^{3}\right)$.

Next, the emission factor (EF) was evaluated from the ER divided by the amount of solvent used, $S$, following Eq. (2)

$$
\mathrm{EF}=\mathrm{ER} / S
$$

\section{Results}

\subsection{Pollution sources and emission characteristics}

Emission characteristics in the major pollution sources were tested and summarized as follows:

(1) Electrodeposition coating: the emitted concentration and ER from electrodeposition coating processes are low, since water-soluble coating materials are applied. To obtain the optimum condition of solvent recovery, controlling VOC emissions at the electrodeposition oven is preferred.

(2) Sealant, PVC soundproof painting, stone-proof painting: the VOCs concentration is extremely low and, therefore, the ER can be neglected. The painting processes are executed in an extremely short time.

(3) Primers coating, top coating: the flue gases from primer and top coatings account for major pollution sources in an automobile plant. A large amount of solvents are added as thinners to adjust the consistency in the application. To effectively lower VOCs emission, it theoretically starts with spray booth improvement. However, the flow rate of air exchange is extremely large (over 10000 $\left.\mathrm{m}^{3} / \mathrm{min}\right)$.

(4) Primer coat, top coat drying: about $70-80 \%$ of VOCs escape from the spray booth, while the remaining $15 \pm 5 \%$ is gradually discharged within a dry oven. The results showed that small flow rate and high VOCs concentration in flue gas emitted from the dry oven.

(5) Patching, waxing, anti-rust waxing: final patching process of coating contains a high content of solvents. However, limited volume of coatings (only $0.5 \%$ of total solvent) are applied so that emissions of pollutants are very small.

The species of organic solvents used in automotive industries include toluene, xylene, ethyl acetate, $n$-butyl acetate, and ketone, which have some degree of toxicity. Table 1 summarizes the consumption of solvents in each process. According to Table 1, the amount of solvents used for washing spray gun and base coating is about 1800 and $\approx 700$ ton/year for primer coat and clear coat.

\subsection{The VOC emission characteristics}

This study has performed on site testing of VOC emissions to understand the variance between theoretical ER and real ER. Table 2 summarizes those results, as described in the following: 
Table 1

Solvent consumption in the automotive industry

\begin{tabular}{|c|c|c|c|c|c|c|c|c|}
\hline \multirow[t]{2}{*}{ Process } & \multirow[t]{2}{*}{ ED } & \multirow[t]{2}{*}{ Prime coat } & \multicolumn{3}{|l|}{ Top coat } & \multirow[t]{2}{*}{ Cleaning } & \multirow[t]{2}{*}{ Others } & \multirow[t]{2}{*}{ Summation } \\
\hline & & & Solid & Base & Clear & & & \\
\hline $\begin{array}{l}\text { Ton/year } \\
\%\end{array}$ & $\begin{array}{l}350 \pm 30 \\
4.8 \pm 0.5\end{array}$ & $\begin{array}{l}830 \pm 60 \\
11.6 \pm 0.9\end{array}$ & $\begin{array}{l}540 \pm 60 \\
7.4 \pm 0.8\end{array}$ & $\begin{array}{l}3100 \pm 120 \\
41.5 \pm 1.6\end{array}$ & $\begin{array}{l}840 \pm 70 \\
11.7 \pm 1.0\end{array}$ & $\begin{array}{l}360 \pm 50 \\
5.0 \pm 0.7\end{array}$ & $\begin{array}{l}1300 \pm 110 \\
18.0 \pm 1.6\end{array}$ & $\begin{array}{l}7200 \pm 270 \\
100\end{array}$ \\
\hline
\end{tabular}

(1) Flue gas temperature: temperature of flue gas emitted from spray booth about room temperature, $23 \pm 2{ }^{\circ} \mathrm{C}$. However, about $110 \pm 40{ }^{\circ} \mathrm{C}$ emitted from the prime coat oven.

(2) Flow rate: the flow rate of flue gas emitted from prime coat booth and topcoat booth is about $2640 \pm 1820$ and $2850 \pm 1770 \mathrm{Nm}^{3} / \mathrm{min}$, respectively. Whereas, it is only $460 \pm 240,80 \pm 50$, and $150 \pm 70 \mathrm{Nm}^{3} / \mathrm{min}$, individually, emitted from ED oven, prime coat oven, and top coat oven depending on the type of drying. Moreover, the flow rate depends on the design of the air exchange equipment.

(3) VOCs concentration: the concentration of flue gas emitted from the primer coat booth and top coat booth is about $480 \pm 320$ and $610 \pm 250 \mathrm{mg} / \mathrm{Nm}^{3}$, respectively, depending on the design of air exchange equipment and the flow rate of the flue gas. Whereas, it is $640 \pm 420,840 \pm 560$, and $1960 \pm 1040 \mathrm{mg} / \mathrm{Nm}^{3}$, respectively, emitted from ED oven, primer coat oven, and topcoat oven dependent on the type of drying.

(4) ER: VOC emissions rate emitted from primer coat booth and topcoat booth is roughly $880 \pm 270$ and $2080 \pm 1210 \mathrm{~g} / \mathrm{min}$, respectively. However, the value ranges from $70 \pm 30,60 \pm 40$, and $190 \pm 80 \mathrm{~g} / \mathrm{min}$, emitted from $\mathrm{ED}$ oven, prime coat oven, and topcoat oven, respectively.

Table 2

Emission characteristics of flue gas from spray booth and oven

\begin{tabular}{lcccc}
\hline Process & $\begin{array}{l}\text { Temperature } \\
\left({ }^{\circ} \mathrm{C}\right)\end{array}$ & ER $(\mathrm{g} / \mathrm{min})$ & Flow rate $\left(\mathrm{Nm}^{3} / \mathrm{min}\right)$ & Concentration $\left(\mathrm{mg} / \mathrm{Nm}^{3}\right)$ \\
\hline Spray booth & & & & \\
Prime coat & $23 \pm 2$ & $880 \pm 270$ & $2640 \pm 1820$ & $480 \pm 320$ \\
Top coat & $23 \pm 3$ & $2080 \pm 1210$ & $2850 \pm 1770$ & $610 \pm 250$ \\
Oven & & & & \\
ED & $140 \pm 40$ & $70 \pm 30$ & $460 \pm 240$ & $640 \pm 420$ \\
Prime coat & $110 \pm 40$ & $60 \pm 40$ & $80 \pm 50$ & $840 \pm 560$ \\
Top coat & $23 \pm 3$ & $190 \pm 80$ & $150 \pm 70$ & $1960 \pm 1040$ \\
\hline
\end{tabular}


Table 3

Comparison between ER of spray booth and oven

\begin{tabular}{|c|c|c|c|c|c|c|}
\hline & & \multicolumn{5}{|c|}{ Plant } \\
\hline & & A & $\mathrm{B}$ & $\mathrm{C}$ & $\mathrm{D}$ & $\mathrm{E}$ \\
\hline \multicolumn{7}{|l|}{ Prime coat } \\
\hline \multirow[t]{2}{*}{ Spray booth } & $\mathrm{ER}(\mathrm{g} / \mathrm{s})$ & 25.9 & 10.2 & 11.5 & 13.8 & 11.9 \\
\hline & Emission ratio $(\%)$ & 93.5 & 97.1 & 93.0 & 89.7 & 94.6 \\
\hline \multirow[t]{2}{*}{ Settling room } & $\mathrm{ER}(\mathrm{g} / \mathrm{s})$ & - & 0.1 & 0.5 & - & - \\
\hline & Emission ratio $(\%)$ & - & 1.3 & 4.4 & - & - \\
\hline \multirow[t]{2}{*}{ Oven } & $\mathrm{ER}(\mathrm{g} / \mathrm{s})$ & 1.8 & 0.2 & 0.3 & 1.6 & 0.7 \\
\hline & Emission ratio $(\%)$ & 6.5 & 0.7 & 2.7 & 10.3 & 5.4 \\
\hline \multicolumn{7}{|l|}{ Top coat } \\
\hline \multirow[t]{2}{*}{ Spray booth } & $\mathrm{ER}(\mathrm{g} / \mathrm{s})$ & 37.3 & 25.0 & 12.0 & 57.5 & 22.9 \\
\hline & Emission ratio $(\%)$ & 93.1 & 98.2 & 83.3 & 90.2 & 98.2 \\
\hline \multirow[t]{2}{*}{ Settling room } & $\mathrm{ER}(\mathrm{g} / \mathrm{s})$ & - & 0.4 & 1.4 & - & - \\
\hline & Emission ratio $(\%)$ & - & 1.5 & 9.5 & - & - \\
\hline \multirow[t]{2}{*}{ Oven } & $\mathrm{ER}(\mathrm{g} / \mathrm{s})$ & 2.8 & 0.1 & 1.0 & 6.2 & 0.4 \\
\hline & Emission ratio $(\%)$ & 6.9 & 0.3 & 7.2 & 9.8 & 1.8 \\
\hline
\end{tabular}

Table 3 compares VOCs emission between spray booth and dry oven in various plants. According to Table 3, ER from topcoating is higher, i.e. $\approx 2.5$-fold that from the primer coat. Generally, the ER from primer coat is higher, i.e. $\approx 2-10$ times that from electrodeposition coat, since the waterborne solvent is used in the later one.

\subsection{Estimating the ER}

In our study, VOC EFs from each plant ranges from 500 to $650 \mathrm{~g}$-VOC/1 coating. Topcoat includes two types: solid coat and metallic coat. Furthermore, metallic coat involves a more complex manufacturing process consisting of base coat and clear coat. Base coat generally involves the most severe degree of pollution. The amount used in base coat ranges from 750 to $800 \mathrm{~g}$-VOC/l coating, while $\approx 500-$ $600 \mathrm{~g}-\mathrm{VOC} / 1$ coating is in solid coat and clear coat. According to statistical data, roughly 400000 cars were produced in 2000 (Industrial Pollution Control Center, 2000). Furthermore, the VOC ER is about 6000 ton/year, so that the EF of coating processes in the automotive industries accounts for $15 \mathrm{~kg} / \mathrm{unit}$ and $580 \mathrm{~g}-\mathrm{VOC} / 1$ coating assuming the consumption of coating of $\approx 10650000$ 1/year (after dilution). The VOC ERs can also be calculated from the measured data, as given in Table 4. Those results demonstrate the following:

(1) Most of VOC emissions ( $83 \%$ of the total) originate from topcoat, primer, and electrodeposition application.

(2) Significant amounts (10\%) of VOC emissions are from solvents used to cleanup vehicles and equipment. 
(3) Less than $8 \%$ of VOC emissions come from all other coating uses.

\section{Discussion}

The results demonstrate that the ERs from the oven are smaller than that from the booth. The small flow rate and high VOC concentration in flue gas emitted from the dry oven allows us to easily treat the pollutants from the oven flue gas.

\subsection{Potential emission reductions}

Two methods are available to reduce VOCs ERs: (a) improve the coating, such as decreasing the solvent content in the painting, and (b) control the VOC ERs of the flue gas in the stack. The former comprises of using waterborne coatings, high-solid coatings, and powder coatings. In general, the $35 / 62 \%$ solid limit coatings are the most conventionally used paintings. The solid limit implies that it requires the use of a $35 \%$ volume solids topcoat and a $62 \%$ equivalent solids primer. Conventional solvent-borne topcoats range from 13 to 35 volume percent solids. Based on information from the automotive and coating industry, major research and development programs are underway to develop low solvent coatings and control equipment. Although the low solvent content coatings can reduce the VOC ERs, working with this kind of paints is more difficult. We assess several coatings.

Table 4

Comparison between data of measurement and estimates

\begin{tabular}{llccl}
\hline Plant & Process & $\begin{array}{c}\text { Measured data } \\
(\mathrm{kg} / \text { day })\end{array}$ & $\begin{array}{l}\text { Estimated data } \\
(\mathrm{kg} / \text { day })\end{array}$ & Measured/estimated (\%) \\
\hline A & ED & 29 & 68 & 43 \\
& Prime coat & 778 & 847 & 91 \\
& Top coat & 2296 & 2560 & 90 \\
B & ED & 138 & 152 & 90.60 \\
& Prime coat & 531 & 647 & 79 \\
& Top coat & 1284 & 2122 & 61 \\
& Bumper & 151 & 160 & 94 \\
C & ED & 77 & 82 & 73 \\
& Prime coat & 623 & 652 & 95 \\
& Top coat & 724 & 2402 & 30 \\
D & ED & 38 & 66 & 42 \\
& Prime coat & 545 & 167 & 62 \\
& Top coat & 1661 & 601 & 96 \\
E & ED & 40 & 65 & 62 \\
& Prime coat & 140 & 167 & 84 \\
& Top coat & 550 & 600 & 92 \\
\hline
\end{tabular}




\subsubsection{Use of waterborne coatings}

The VOC emission from waterborne coatings can be absorbed in water. A major cost of converting to the waterborne system is the required lengthening or widening of spray booths, flash tunnels, and bake ovens. Such extensions allow the water in the coating to evaporate slowly. This practice also prevents pitting, boiling, and running of the coating, in case a $70 \%$ solids coating is developed. A related application of the waterborne coating system is necessary for the air conditioning of the spray booths, which is costly. In Plant A, the assessed cost of installing waterborne coating system is about 30000000 US dollar or 28000 dollars $/ \mathrm{Nm}^{3}$. The predicted reduction ER is about $350 \mathrm{gVOCs} / 1$ coating or 800 tonVOCs/year in Plant A.

\subsubsection{High-solids coatings}

High-solids coatings consist of urethane enamels and powder coatings.

4.1.2.1. Urethane enamels. Urethane enamels offer a potential emission reduction in solvent usage of up to $90 \%$, considerable energy savings from conventional systems and enhanced physical properties and surface luster. Advanced technology for urethane enamels has largely focused on developing one-component and two-component types. The two component systems have application problems and equipment is currently being developed, which will be reliable for practical use under manufacturing conditions. Two-component products are currently undergoing outdoor durability and laboratory testing.

Although initial results on the one-component urethane are quite promising, the product is several years away from commercialization. Commercialized products have a $60 \%$ solid content, However, the one-component urethane appears to be highly promising for attaining a higher than $70 \%$ solids content. A potential drawback to the urethane coating is the isocyanate ingredient in the coating. Although uncertain at this time, isocyanates may be toxic to humans. Moreover, the presence of isocyanates may require additional control measures to prevent occupational exposures during the coating operation (US EPA, 1977). In Plant A, the assessed cost of using urethane enamels is about 7000000 US dollar or 6500 dollars $/ \mathrm{Nm}^{3}$. The predicted reduction $\mathrm{ER}$ is about $82 \mathrm{gVOCs} / 1$ coating or 180 tonVOCs/year.

4.1.2.2. Powder coatings. Preliminary studies indicate that powder coatings reduce the energy requirements and VOCs emissions. With powder recovery and re-use, utilization efficiency can exceed 95\%. However, the powder coating is severely limited as a top coating in that it is not yet feasible to develop an appropriate range of metallic colors. This obstacle appears to be inherent in the physics of the coating film formation and may never be overcome. The cost of using powder coatings is about 10000000 US dollar or 9300 dollars $/ \mathrm{Nm}^{3}$ in the same plant. The calculated reduction ER is about $80 \mathrm{gVOCs} / 1$ coating or 160 tonVOCs/year. 


\subsection{Economic impact}

The potential economic impacts of the proposed rule fall into two categories: (a) additional costs to the company (a large proportion is likely to be passed along to consumers) and (b) any changes in employment at the plants due to the control effects. The latter is not adverse, since no reduction in employment is implied by any of the control alternatives. However, the first category includes a higher cost of any additional labor required.

The costs must be compared to evaluate the alternatives of control strategies to be established by the rule. Higher total costs do not necessarily imply that an alternative should be omitted, since greater emission reductions may result. Therefore, the costs should be compared and based on ER reduced.

\section{Conclusions}

Several solvents are used as a thinner in coating processes. VOCs are emitted from painting booths and ovens. The measured results in five factories indicate that the major pollutants are toluene, xylene, ethyl acetate, and butyl acetate. Furthermore, the dominant pollution sources are located at the primer and enamel booth, emitting $83 \pm 3 \%$ total VOCs ERs. Generally, emitted VOC concentrations are about $30 \pm 15 \mathrm{ppm}$ from the booth and about $125 \pm 45 \mathrm{ppm}$ from the oven. The flow rate is $2650 \pm 1250 \mathrm{Nm}^{3} / \mathrm{min}$ from booth and $450 \pm 350 \mathrm{Nm}^{3} / \mathrm{min}$ from oven. ERs of VOC also depend on methods of operation. In general, VOC ERs from auto-spray booths are $50 \%$ higher than from manual spray booths.

\section{References}

Air Resources Board. Proposed Model Rule for the Control of Volatile Organic Compounds from Automobile Assembly-line Coating Operations State of California, USA, 1978.

Chang C-T, Jeng F-T. Study on the strategies of waste solvent minimization in automobile production industry. In: 91th Annual Meeting and Exhibition of Air and Waste Management Association, June 14-18, San Diego, California, USA, 1998.

Ergas SJ. Control of volatile compound emission from a POTW using a compost biofilter. In: Proceedings of the 85th Annual Air and Waste Management Association Meeting and Exhibition, Kansas City, Missouri, June 21-26, 1993.

Findlay GE, Nirmalakhandan N. Biological treatment of airstreams contaminated with VOCs: an overview. Water Science Technology 1996;34:565-71.

$\mathrm{Fu} \mathrm{L}$, Hao J, He D, He K. Assessment of vehicular pollution in China. Journal of the Air and Waste Management Association 2001;51:658-68.

Industrial Pollution Control Center, China Technical Consultants. The Project of Investigation of VOCs Emission in Automobile Industry, 2000.

Japanese EPA. Motor Vehicle Pollution and its Control in Japan, Tokyo, Japan, 1999.

National Archives and Records Administration. Code of Federal Regulation 40-Part 60, Office of the Federal Register, USA, 1998.

Smith CM, Brown WE. Elimination of VOCs emissions from surface coating operations. Journal of Air and Waste Management Association 1993;43:1015-21. 
Tichenor BA, Palazzolo MA. Destruction of volatile organic compounds via catalytic incineration. Environmental Progress 1997;16(3):223-43.

US EPA. Control of Volatile Organic Emissions from Existing Stationary Sources, Vol. II-Source Coating of Cans, Coils, Papers, Fabrics, Automobiles, and Light-Duty Trucks, EPA-450/2-77-008, 1977.

Wadden RA, Scheff PA, Franke JE, Controy LM. Determination of VOC emission rates and compositions for offset printing. Journal of Air and Waste Management Association 1995;45:54755.

Wolkoff P, Wilkins CK, Clausen PA, Larsen K. Comparison of volatile organic compounds from processed paper and toners from office copiers and printers. Indoor Air 1999;10:113-23. 